\title{
基于化工卓越人才培养的化工原理实验教学模式改革与探索
}

陈金金，董亮亮，涂国云，张春芳，白云翔

江南大学化学与材料工程学院, 江苏无锡 214122

摘要: 卓越工程人才培养是 “新工科” 建设的核心, 针对目前化工原理实验课程教学中出现的问题和不足, 江南大 学从 “新工科” 建设视域下, 积极探索化工原理实验教学改革, 突出教学与育人相结合, 为培养科研创新能力强、 工程实践能力强、社会责任感强和国际化视野强的“四强” 化工卓越人才奠定基础。

关键词: 新工科; 化工原理实验; 教学改革; 化工卓越人才

中图分类号: G64; O6

\section{Exploration of Reform on Teaching of the Chemical Engineering Principle Laboratory Based on Chemical Outstanding Engineers Cultivation}

\author{
Xin Chen, Liangliang Dong *, Guoyun Tu, Chunfang Zhang, Yunxiang Bai \\ School of Chemical \& Material Engineering, Jiangnan University, Wuxi 214122, Jiangsu Province, China.
}

\begin{abstract}
Outstanding engineer cultivation is the core objective of emerging engineering education. In view of the problems in the current laboratory practice of chemical engineering principles, Jiangnan University explores laboratory teaching reform of chemical engineering principles from the perspective of emerging engineering education, which aims to intensify the combination of imparting knowledge and educating people. This new laboratory teaching system lays a foundation for the cultivation of chemical outstanding engineers with high research and innovation ability, engineering practice ability, sense of social responsibility and international vision.
\end{abstract}

Key Words: Emerging engineering education; Chemical engineering principle laboratory;

Teaching reform; Chemical outstanding engineers

高等教育发展水平是一个国家发展水平和发展潜力的重要标志。习近平总书记指出 ${ }^{[1]}$, “我们对 高等教育的需要比以往任何时候都更加迫切, 对科学知识和卓越人才的渴求比以往任何时候都更加 强烈。” 人才的竞争在当前新一轮科技革命与产业变革中的重要性愈加凸显, 为此, 教育部相继印发 了《教育部关于加快建设高水平本科教育全面提高人才培养能力的意见》等文件, 决定实施 “六卓 越一拔尖” 计划 2.0 , 即新工科建设, 旨在培养具有创新创业能力、工程实践能力和高素质的交叉复 合型科技人才 ${ }^{[2,3]}$ 。

化工原理实验是化学化工类专业人才培养中一门重要的基础核心课程, 是化工原理从基本理论 走向工程实践的桥梁, 不仅能够加深学生对于理论知识的理解, 还可以培养学生的工程概念和工程 意识 ${ }^{[4]}$ 。然而, 随着新工科建设的提出, 现有的化工原理实验课程教学模式和方法已难以满足化工

收稿: 2021-05-26; 录用: 2021-07-22; 网络发表: 2021-09-01

“通讯作者, Email: liangliangdong@jiangnanl.edu.cn

基金资助：江南大学本科教育教学改革研究项目(JG2019110) 
卓越人才培养的要求。因此, 在化工卓越人才培养视域下, 积极探索全新的化工原理实验课程教学 模式, 是推动化工原理实验课程教学向纵深发展的必经之路。

本文结合化工原理实验课程教学现状及面临的挑战, 着眼于课程内涵建设, 以成果导向教育理 念(outcomes-based education, OBE)为指导, 提出 “四强” 化工卓越人才培养理念, 以科研创新能力、 工程实践能力、社会责任感和国际化视野4个方面能力的培养为核心，从课程教材、实验内容、虚拟 仿真、实验竞赛、课程思政等多个维度进行化工原理实验课程教学改革, 形成系统性的化工原理实 验课程教学新体系。

\section{1 化工原理实验课程现状}

化工原理实验是一门以化工单元操作和设备为主的实践性课程, 旨在通过实验加深和巩固学生 对化工单元操作基本原理、计算方法等的理解, 培养学生分析和解决实际问题的能力, 提高学生的 沟通、协作及动手能力。随着化工卓越人才培养计划的深入实施, 现有的化工原理实验课程教学日 益凸显出其不足之处, 主要体现在以下几个方面:

(1) 教学体系有待进一步优化。

目前的化工原理实验课程教学仍普遍存在 “满堂灌” “填鸭式” 的教学模式, 导致师生之间缺 乏互动, 降低了学生的学习热情, 从而制约了教学质量的提高 ${ }^{[5]}$ 。现行的高校评价体系也使得大多 数工科教师普遍存在 “重科研轻教学” 的现象, 教学过程中往往 “照本宣科”, 课程内容陈旧, 不 注重对最新科技进展和成果的讲解, 缺乏对教学方法和内容创新的动力。同时, 我校化工原理实验 虽然在常规实验方面已给予了学生动手及合作能力的培养, 但在化工基础安全及大型实训方面仍存 在缺失, 难以有效培养学生的创新能力、工程应用能力和独立思考能力, 教学体系有待优化。

(2) 课程思政元素有待深掘。

目前, 在校大学生基本都是 00 后, 自理能力较差, 缺乏团队意识。绝大部分学生只注重专业知 识和专业技能的学习, 对思想政治教育的重要性认识不足; 特别是近年来全球化国际化进程不断加 速, 西方国家的一些生活方式和价值观已经渗透到了学校, 导致部分学生的价值取向发生扭曲, 理 想信念有所缺失 ${ }^{[6,7]}$ 。化工原理实验虽是一门实验课程, 但其中也蕴含了丰富的课程思政。我校教师 在授课过程中很少能够根据课程内容与思政教育相关联, 实践教学的育人功能未能得到充分发挥, 难以与其他课程协同实现全方位育人。

(3) 国际化视野有待拓宽。

培养具有全球意识、跨文化交流、通晓国际规则、参与国际合作竞争的卓越人才是中国经济全 球化发展的当务之急。传统的化工原理实验教学中突出对单元操作基本知识的熟练掌握和灵活应用, 但在全球经济一体化趋势下, 对卓越人才培养应具备的国际视野和跨文化交流能力的培养略显不足, 专任教师对国际化的实验教学理念认识不够深入。

\section{2 化工原理实验课程教学改革实践}

针对上述问题, 江南大学的化工类专业从实验教学、虚拟仿真、课程思政和国际化视野等方面 开展化工原理实验课程教学改革, 突出 “四强” 化工卓越人才培养理念, 积极探索全新的教学模式 与体系, 着力提升学生的工程素质和实践能力。具体改革举措如图1所示。

\section{1 优化实验教学体系, 提高学生科研创新能力}

OBE教育理念注重强调学生的 “学” 而非教师的 “教”, 教学过程中更加突出学生的主体地位, 充分发挥学生的主观能动性 ${ }^{[8]}$ 。江南大学化学与材料工程学院在承担了全校几乎所有化工相关专业 实验的基础上, 结合 $\mathrm{OBE}$ 教育理念, 根据不同专业的培养目标开设了 “个性化” 实验。为适应 “现 代分离技术” 等创新性课程的需要, 建立较为完整且具有专业针对性的膜分离实验教学内容, 涵盖 本校各工科专业, 开展发酵液、酶及蛋白等分离, 物料、果汁、天然药物及活性物提取、废水资源 


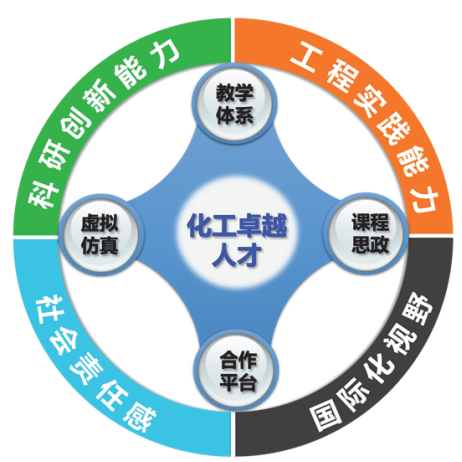

图1“四强”化工卓越人才培养理念

化处理等与各专业密切相关的实验教学内容; 为强化非均相物系分离教学效果与工程能力培养, 在 原有箱式干燥器的基础上增设流化床干燥器, 主要为我校生物工程和食品工程学科学生提供产品干 燥过程的实验研究方法锻炼的平台; 基于天然物质萃取教学与研究的需要, 增设连续萃取和转盘萃 取两种实验装置, 用于制药和食品专业中的天然药物提取、食品添加剂分离等, 使教学更贴近于本 校专业特色。通过对实验教学方案与设备的精心设计, 能够满足课题试验方案、数据采集、结果分 析等要求的关键元素, 提高了学生的科研创新能力, 使得实验教学满足本科教学的同时, 也适应研 究生 “现代分离技术” “化工专题” 等课程学习与课题研究的需要, 构建本科教学与研究生培养直通 式的实验教学平台。

目前我校化工原理实验装置已向全校本科生课外研究及毕业论文研究开放, 近几年学生利用教 学平台进行开放性的科学研究, 仅在膜分离方面就获得国家级大学生创新创业训练计划(大创)项目 2 项, 校级大创项目 2 项, 以及 1 项已授权的发明专利。同时在大学生化工原理实验竞赛及大学生化工 设计大赛中屡屡获奖(图2)。
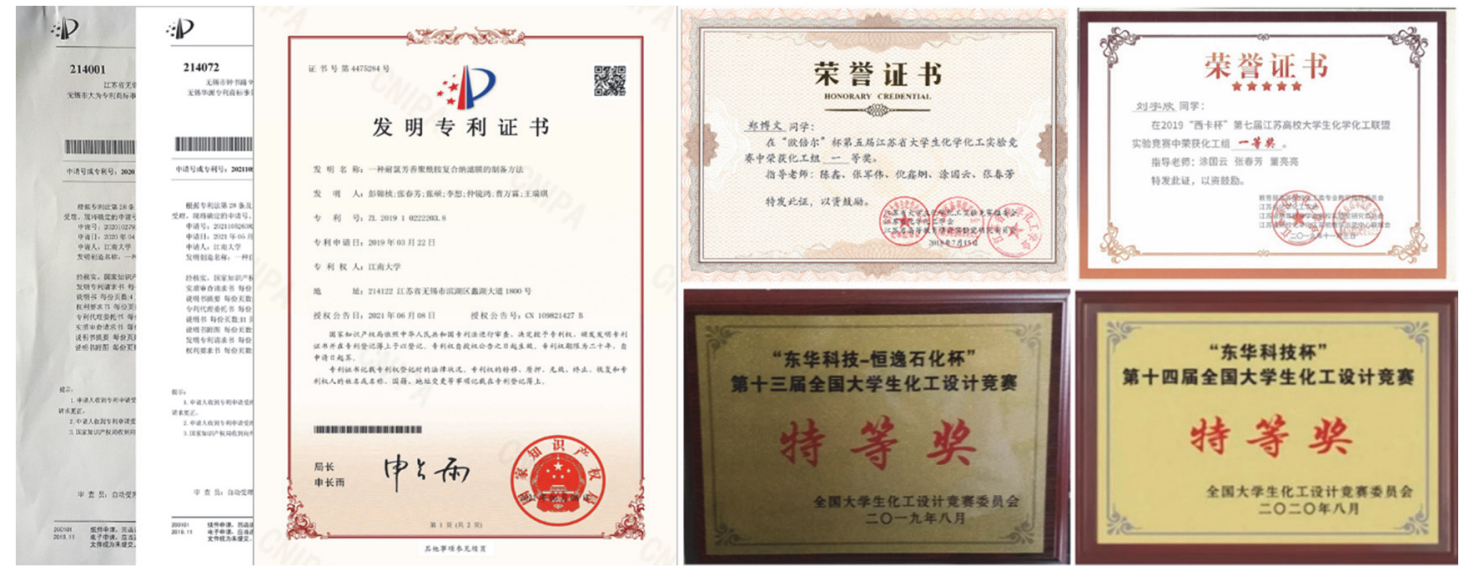

图2 发明专利及获奖证书

\section{2 建立仿真实验体系, 增强学生的工程实践能力}

OBE教育理念注重学生的学习效果与体验。我校化工原理实验室目前开设了流体流动阻力实验、 离心原性能曲线测定、恒压过滤常数测定、换热器传热系数测定、蒸发传热系数测定、精馏塔全塔 效率测定、吸收系数测定、萃取率测定、干燥速率曲线测定、膜分离通量曲线测定等实验, 还有离 心百气蚀及固体流态化等选做实验, 同时每个实验的台套数基本都保证在 8 台, 学生在做这些实验时 动手能力以及协同合作能力可以得到很好的培养, 但这对于化工类学生还远远不够。 
学院围绕化工卓越人才培养的需要, 建立了新型的仿真实验体系(图3)。通过实验设备构造拆解 展示、实验过程演示、在线操作模拟、工厂实习模拟、突发问题分析与排除等环节, 展现逼真的实 验室场景、实验现象及工厂实际场景, 通过人机交互活动达到辅助实验教学的目的, 形成了 “预 习-仿真-操作-报告” 四位一体、“课内-课外” 相互补充的化工原理实验教学体系, 培养了学生处理 突发问题的能力, 增强了学生的安全意识和自救能力。
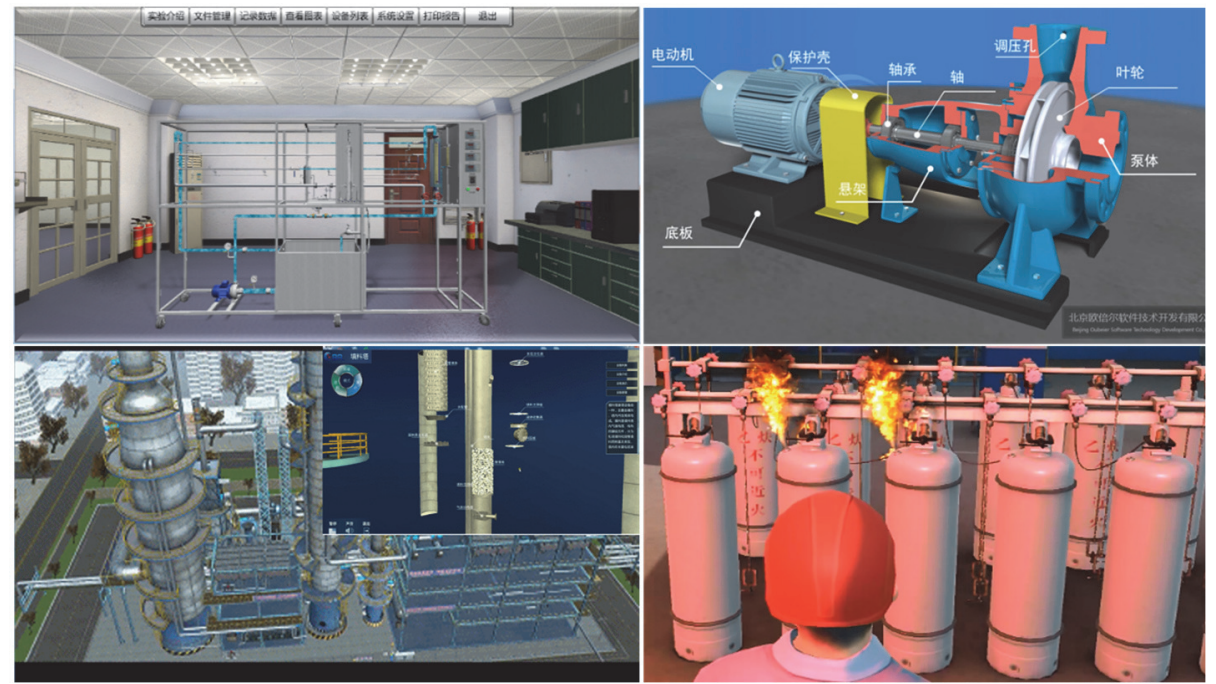

图3 化工原理虚拟仿真实验教学系统

\section{3 将课程思政引入教学, 增强学生的社会责任感}

新形势下, 对大学生进行思想政治教育必须贯穿于每一门课程之中，构建全学科、全方位、全 时段的思想政治教育新模式。我院目前不仅开设专门的思政课程, 也要求每门课程融入思政教育。 对于化工原理实验课程(表1), 我们一方面在实验教学中注重培养学生运用辩证唯物主义观点和科学 方法考查、分析和处理工程实际问题; 另一方面, 采用隐性渗透式、课堂讨论式、启发式等教学模 式, 将家国情怀、爱国主义、理想塑造、科学精神、工程伦理等育人德育元素融入实验教学中, 寓 德于教, 培养学生树立正确的社会主义核心价值观。

\section{表1 化工原理实验课程中的思政元素}

\begin{tabular}{lll}
\hline \multicolumn{1}{c}{ 实验内容 } & \multicolumn{1}{c}{ 思政切入点 } & \multicolumn{1}{c}{ 思政元素 } \\
\hline 流体流动阻力实验 & 牛顿、雷诺、顾毓珍等科学家; 直管阻力损失 & 创新科学精神、民族自豪感、社会责任感、逻辑思辨能力 \\
离心百性能曲线测定 & 离心洜的管路和选型、伯努利方程 & 领悟科学思维、掌握研究方法、探索精神、环保理念 \\
换热器传热系数测定 & 流量计的校正 & 科学严谨的态度 \\
蒸发传热系数测定 & 在求解时反复迭代试差 & 提高抗挫能力 \\
精馏塔效率测定 & 回流比、溶剂回收、冷凝水再利用 & EHS理念(环境Environment、健康Health、安全Safety) \\
吸收系数测定 & 液气比、尾气处理 & 资源有效利用、绿色化工理念 \\
萃取率测定 & 溶剂用量、废液处理、分离过程 & 资源有效利用、绿色化工理念、量变到质变的哲学观点 \\
\hline
\end{tabular}

\section{4 打造双语课程教学, 增强学生的国际化视野}

“一带一路” 国家发展战略的提出对人才培养提出了新的要求, 尤其是对具有国际视野的外向 型各类工程人才的需求变得日益迫切。同时, 教育部的 “新工科” 建设也把培养具有国际视野的卓 越工程技术人才作为工程教育改革的一项重要措施。为此, 我校增加了化工原理的英语教学, 让学 
生掌握化工原理方面的专业英语词汇; $90 \%$ 以上的化工原理实验课程教师具有海外访学经历, 实现 师资国际化; 实验课程的任课教师邀请海外知名专家到学校进行工程方向的学术交流, 让学生了解 到国际前沿的化工技术; 修订实验的教学大纲及课程评价方法, 满足工程教育专业认证的国际化标 准; 借鉴国外的先进教育方式和成熟教学案例, 丰富实验教学内容; 将国外教材作为补充教材, 开 拓学生的国际化视野。

\section{3 结语}

“新工科”建设是深化我国高等工程教育改革的一次战略机遇, 也为化工卓越人才培养指明了 新方向。我校化学工程与工艺专业于2017年通过中国工程教育专业认证, 这既是对我校工程教育质 量的肯定, 同时也对我校工程人才的培养提出了更高的要求。因此, 我校在化工卓越人才培养视域 下重新审视化工原理实验课程教学, 通过教学体系优化、课程思政导入、双语课程教学等措施, 对 化工原理实验教学体系进行多维度改革。通过上述改革与探索, 构建以 “四强” 化工卓越人才培养 为核心的化工原理实验课程教学新体系, 有效地提升实验课程的教学质量, 促进学生的科研创新能 力、工程实践能力、社会责任感和国际化视野的全面提升, 进而支撑卓越工程人才的培养。

\section{参 考 文 献}

[1] 习近平在全国高校思想政治工作会议上强调: 把思想政治工作贯穿教育教学全过程开创我国高等教育事业发展新局面.

人民日报, 2016-12-09.

[2] 杜可杰, 林英武, 伍智林, 侯三英, 贺楚华. 教育现代化, 2019, No. 66, 10 .

[3] 孟洪, 张玮, 王俊文, 陈晓春. 化工高等教育, 2020,37 (4), 97.

[4] 刘建军, 徐向阳, 冯庆华, 常彦龙. 大学化学, 2016, 31 (5), 23.

[5] 吕丹丹, 郑建东, 张伟钢, 冯建华, 王余杰, 马田林. 化工教育, 2021, 50 (3), 203.

[6] 陈立钢, 牛娜, 孙明礼. 高教论坛, 2019, No. 4, 58.

[7] 刘淑明, 严菊芳, 张丁玲, 穆婉红. 教育理论与实践, 2019, 39 (15), 44.

[8] 潘鹤林, 黄婕, 叶启亮. 化工高等教育, 2018, 35 (5), 25. 